EDITORIAL

\title{
Practising what is preached: the MINAP study
}

\author{
O C Raffel, H D White
}

Heart 2004;90:969-971. doi: 10.1136/hrt.2004.036251

\section{Many patients with acute coronary syndromes do not receive evidence based treatments, and treatment standards vary significantly within and between countries}

O ver the past two decades, findings from randomised controlled trials have revolutionised the treatment of patients with acute coronary syndromes (ACS). Clinical practice guidelines have been drawn up nationally and internationally to integrate the vast wealth of trial findings into up-to-date, clinically relevant treatment strategies. ${ }^{1-4}$ So can patients who present to their local hospital with an ACS be assured that the treatment they receive is appropriate, evidence based, and in accordance with current guidelines? Studies worldwide have found that they cannot, ${ }^{56}$ and that few doctors perform consistently as well as they should. Many of us do not practise what we preach.

Findings from registries and large randomised clinical trials show that many patients with ACS do not receive evidence based treatments, and that treatment standards vary significantly within and between countries. ${ }^{56}$ It is therefore remarkable to read the report from the Myocardial Infarction National Audit Project (MINAP), ${ }^{7}$ published in this issue of Heart, which reveals that patients hospitalised with ACS in England or Wales actually have very high usage rates of evidence based treatments.

\section{MINAP DATABASE}

The MINAP database was developed to meet the audit requirements of the UK National Service Framework (NSF) for coronary heart disease, which was published in March 2000. ${ }^{4}$ The database started enrolling patients in October 2000 and now includes all hospitals in England, and all but one hospital in Wales, that manage patients with ACS. To date, 195095 patients presenting for treatment with suspected ACS have been enrolled in the database, of which 156902 had electrocardiographic or biochemical marker evidence of ACS. Of these, 53208 patients were diagnosed with ST elevation ACS on the basis of their electrocardiographic features at admission. Of the patients who presented to hospitals with ST elevation ACS, 83.5\% received thrombolytic treatment, $11.5 \%$ did not receive it for documented reasons, and 5\% had thrombolytic treatment withheld for no obvious reason. Between the first and last six months of the study, the median "door-to-needle" time fell from 38 minutes to 20 minutes, and the proportion of eligible patients receiving thrombolytic treatment within 30 minutes of arrival at hospital increased from $42.6 \%$ to $77.6 \%$ $(p<0.0001)$. Similarly, the proportion of eligible patients receiving thrombolytic treatment within 60 minutes of first contact with emergency or medical services rose from $19.9 \%$ to $46.7 \%(\mathrm{p}<0.0001)$. The report also details the secondary preventative medication prescribed at discharge in all cases of ACS. The proportions of patients receiving aspirin, $\beta$ blockers, angiotensin converting enzyme (ACE) inhibitors, and statins increased significantly over the three year course of the study, and usage rates of these treatments were high in the last six months (table 1). The authors ascribe all of these improvements to both the setting of national targets and to the immediate analysis and feedback provided to clinicians by their electronic audit system.

It is possible that the uptake of evidence based therapies into routine clinical practice would have occurred over time even without the institution of MINAP. However, the study had no control group of non-participant hospitals with which to make comparisons. Another point to note is that different numbers of hospitals were involved at different times during the period of the study (96 hospitals in 2000 and 230 hospitals in 2003), thus it is possible that the demographic profiles of the patients being added to the database changed over time.

\section{WORRYING TRENDS}

There are some worrying trends in the MINAP dataset. In patients with ST elevation ACS, the median delay from the time patients first noticed their symptoms to the time they acted upon them increased from 75 to 80 minutes over the course of the study, and the proportion of patients who sought help within 30 minutes diminished over time. Moreover, the proportion of patients with any type of ACS who made their own way to hospital rose from $14.1 \%$ to $16.9 \%$ during the study period. While it is acknowledged that most public education campaigns encouraging patients with ACS to present early for treatment have been unsuccessful, it might be worth considering a campaign to encourage the public to summon an ambulance promptly in the event of a suspected ACS.

Abbreviations: ACS, acute coronary syndromes; $A C E$, angiotensin converting enzyme; ACS, acute coronary
syndromes; EUROASPIRE, European Action on Secondary and Primary Prevention Through Intervention to Reduce Events; GRACE, Global Registry of Acute Coronary Events; MINAP, Myocardial Infarction National Audit Project; LDL, low density lipoprotein; NRMI, National Registry of Myocardial Infarction; PROVE-ITTIMI-22, Pravastatin or Atorvastatin Evaluation and Infection Therapy-Thrombolysis in Myocardial Infarction 22 
Table 1 Usage of secondary preventative medications in patients with acute coronary syndromes, as documented by different cardiovascular registries

\begin{tabular}{|c|c|c|c|c|c|c|}
\hline & \multirow{2}{*}{$\begin{array}{l}\text { EUROASPIRE-II } \\
(1999-2000) \\
(n=8181)\end{array}$} & \multirow{2}{*}{$\begin{array}{l}\text { GRACE }^{15 *} \\
(1999-2000) \\
(n=6312)\end{array}$} & \multirow{2}{*}{$\begin{array}{l}\text { Euro Heart Survey } \\
\text { ACS }^{16}(2001) \\
(n=10484)\end{array}$} & \multirow{2}{*}{$\begin{array}{l}\text { NRMI-3 } \\
(1999) \\
(n=213665)\end{array}$} & \multicolumn{2}{|c|}{ MINAP $^{7 *}(n=156902)$} \\
\hline & & & & & $(2000-1)$ & $(2002-3)$ \\
\hline Aspirin (\%) & 90.3 & 91 & 85.4 & $81 \dagger$ & & \\
\hline$\beta$ Blockers (\%) & 66.2 & 7 & 73 & $65 \dagger$ & 76.3 & 82.6 \\
\hline ACE inhibitors (\%) & 37.6 & 55 & 56.9 & $40 \dagger$ & 62.4 & 72.4 \\
\hline Statins (\%) & 42.7 & 47 & 53.0 & 36.2 & 69.9 & 83.8 \\
\hline \multicolumn{7}{|c|}{$\begin{array}{l}\text { *The GRACE and MINAP analyses specifically excluded patients who had contraindications against these } \\
\text { medications. } \\
\text { tThe percentages for aspirin, } \beta \text { blockers, and ACE inhibitors have been calculated for the purpose of this analysis } \\
\text { from data in the NRMI publication. } \\
\text { ACE, angiotensin converting enzyme; ACS, acute coronary syndromes; EUROASPIRE, European Action on } \\
\text { Secondary and Primary Prevention Through Intervention to Reduce Events; GRACE, Global Registry of Acute } \\
\text { Coronary Events; MINAP, Myocardial Infarction National Audit Project; NRMI, National Registry of Myocardial } \\
\text { Infarction. }\end{array}$} \\
\hline
\end{tabular}

A number of other registries have reported changes in prescribing patterns over time, with trends towards greater usage of evidence based treatment and away from nonevidence based treatments (table 1). Unfortunately, the MINAP report does not discuss the use of calcium channel blockers in patients with ACS. ${ }^{58}$

In the GRACE study, ${ }^{6}$ aspirin usage in eligible patients increased from $95.7 \%$ in 1999 to $97.3 \%$ in 2001 ( $p=0.04)$, while $\beta$ blocker usage rose from $86.5 \%$ to $93.7 \%$ ( $p<0.0001$ ). However, the usage of thrombolytic treatment declined from $54.1 \%$ to $47.0 \%$ over the same period $(\mathrm{p}=0.0034)$. Although the percentage of patients undergoing primary PCI (that is, within 12 hours of symptom onset) increased from $15.1 \%$ to $26.7 \%(\mathrm{p}<0.0001)$, the proportion of patients receiving no reperfusion treatment did not change (32.4\% $v 30.2 \%)$. In contrast, only $0.6 \%$ of patients in the MINAP database underwent primary PCI, and $24 \%$ received no reperfusion treatment.

The evidence base for the use of various medications has changed recently. For example, $\beta$ blockers are now recommended rather than contraindicated in patients with heart failure. Surprisingly, the MINAP dataset reveals that the usage of ACE inhibitors was more widespread than was advocated by treatment guidelines of the time. There is now strong evidence for the use of ACE inhibitors in all patients with coronary disease, regardless of left ventricular function or the presence or absence of heart failure, and hence ACE inhibitor usage can be expected to increase even further in the future. ${ }^{9}$ Early use of statins has not generally been recommended in treatment guidelines, but there is now good evidence that patient compliance with statin treatment is improved if treatment is instituted during hospitalisation. ${ }^{10}$ Furthermore, the recent PROVE-IT-TIMI-22 study found that patients started on intensive atorvastatin treatment $(80 \mathrm{mg}$ daily) within 10 days after admission with an ACS achieved lower low density lipoprotein (LDL) cholesterol concentrations $(1.6 \mathrm{mmol} / \mathrm{l} v 2.5 \mathrm{mmol} / \mathrm{l})$ than those started on pravastatin (40 mg daily). Those given atorvastatin also had a $16 \%$ lower incidence of cardiovascular events (including death, myocardial infarction, readmission with unstable angina, revascularisation, or stroke), and the treatment benefit of atorvastatin manifested very early, within the first 30 days. ${ }^{11}$

\section{EVIDENCE BASED MEDICINE}

In our view, evidence based medicine entails not just usage of evidence based treatments, but usage of evidence based dosages of these treatments. The PROVE-IT-TIMI-22 trial showed that greater benefits could be achieved by reducing LDL cholesterol values even further than current guidelines recommend. ${ }^{12}$ It would therefore be interesting to know what statin doses were prescribed in MINAP, and what the patients' LDL values were at follow up. Audits of the blood pressure levels achieved, the usage of $\beta$ blockers in patients with heart failure, and smoking cessation rates would also be valuable. It is hoped that these and many other matters will be addressed in future reports from the MINAP database.

Treatment audits in the early 1990s showed that clinical trial findings had made little impact upon the day-to-day management of patients with ACS, ${ }^{13}$ and indeed it is only in the past few years that large scale efforts have been made to bring treatment practices into line with current knowledge. Clearly, this process is influenced by complex interactions involving multiple factors, and research has shown that it takes more than just the publication of guidelines to ensure the uptake of evidence based treatments into routine practice. ${ }^{14}$ Crucial elements for success include the availability of strong evidence, participation by clinicians in the trials from which the evidence is derived, the presence of strong opinion leaders, dissemination of educational materials, treatment audits with feedback to clinicians, and multifaceted programmes with educational outreach. ${ }^{14}$ A recent systematic review of five different guideline implementation strategies showed that the introduction of treatment audits and feedback produced a $7 \%$ absolute increase in the usage of evidence based treatment strategies. This equates to the increase in $\beta$ blocker usage observed in MINAP, but was exceeded in MINAP by the increases in ACE inhibitor usage $(10 \%)$ and statin usage $(13.9 \%) .{ }^{14}$

Although the data reported from MINAP are of great interest, it is the project itself that is so impressive. Databases and registries are vital components of any systematic initiative to improve clinical practice, as they permit measurement of performance and outcomes with feedback to participating institutions. The MINAP database uses a secure online data entry, transmission, and analysis system. This allows data entry at the point of care using a well defined dataset, which can be revised periodically. Confidentiality is ensured, and patient consent is unnecessary. Institutions can have immediate access to their own up-todate data analyses, and can compare these with national aggregate analyses. Although similar online databases are in use elsewhere, the level of participation among hospitals that manage ACS in England and Wales is significant and unprecedented. The MINAP database is an enormous achievement, and has underpinned substantial advances in the care of patients with ACS in recent years. As the report's authors point out, an audit programme such as MINAP can also act as an early warning system to ensure that these standards are maintained. 
Those responsible for MINAP are to be commended for developing such an excellent registry with impressive coverage of hospitals throughout England and Wales. A lot of collaborative effort has clearly gone into the project at many levels. Perhaps this initiative could be expanded to include other countries, via the use of similar internet based audit systems, to educate and encourage clinicians worldwide to practise what is preached.

\section{Authors' affiliations}

O C Raffel, H D White, Green Lane Cardiovascular Service, Auckland City Hospital, Auckland, New Zealand

\section{REFERENCES}

1 Braunwald E, Antman EM, Beasley JW, et al. ACC/AHA guideline update for the management of patients with unstable angina and non-ST-segment elevation myocardial infarction - 2002: summary article: a report of the American College of Cardiology/American Heart Association task force on practice guidelines (committee on the management of patients with unstable angina). Circulation 2002;106:1893-900.

2 Bertrand ME, Simoons ML, Fox KAA, et al. Management of acute coronary syndromes in patients presenting without persistent ST-segment elevation: the task force on the management of acute coronary syndromes of the European Society of Cardiology. Eur Heart J 2002;23:1809-40.

3 Van de Werf F, Ardissino D, Betriu A, et al. Management of acute myocardial infarction in patients presenting with ST-segment elevation: the task force on the management of acute myocardial infarction of the European Society of Cardiology. Eur Heart J 2003;24:28-66.

4 UK Department of Health. Coronary heart disease: national service framework for coronary heart disease: modern standards and service models [monograph on the internet]. London: Department of Health; 2000 [cited 2004 May 3]. Available from: http://www.dh.gov.uk/assetRoot/04/04/90/ 70/04049070.pdf.

5 EUROASPIRE I and II Group. Clinical reality of coronary prevention guidelines: a comparison of EUROASPIRE I and II in nine countries. Lancet 2001;357:995-1001

6 Fox KAA, Goodman SG, Anderson FA Jr, et al. From guidelines to clinical practice: the impact of hospital and geographical characteristics on temporal trends in the management of acute coronary syndromes: the global registry of acute coronary events (GRACE). Eur Heart J 2003;24:1414-24.
7 Birkhead JS, Walker L, Pearson M, et al. Improving care for patients with acute coronary syndromes: initial results from the national audit of myocardial infarction project (MINAP). Heart 2004;90:1004-9.

8 Reikvam A, Kvan E, Aursnes I. Use of cardiovascular drugs after acute myocardial infarction: a marked shift towards evidence-based drug therapy. Cardiovasc Drugs Ther 2002;16:451-6.

9 The European Trial on Reduction of Cardiac Events With Perindopril in Stable Coronary Artery Disease Investigators. Efficacy of perindopril in reduction of cardiovascular events among patients with stable coronary artery disease: randomised, double-blind, placebo-controlled, multicentre trial (the EUROPA study). Lancet 2003;362:782-8.

10 Muhlestein JB, Horne BD, Bair TL, et al. Usefulness of in-hospital prescription of statin agents after angiographic diagnosis of coronary artery disease in improving continued compliance and reduced mortality. Am J Cardiol $2001 ; 87: 257-61$

11 Cannon CP, Braunwald E, McCabe $\mathrm{CH}$, et al. Intensive versus moderate lipid lowering with statins after acute coronary syndromes. N Engl J Med 2004;350: 1495-504.

12 National Cholesterol Education Program (NCEP) Expert Panel on Detection, Evaluation, and Treatment of High Blood Cholesterol in Adults (Adult Treatment Panel III). Third report of the National Cholesterol Education Program (NCEP) expert panel on detection, evaluation, and treatment of high blood cholesterol in adults (adult treatment panel III) final report. Circulation 2002; 106:3143-421.

13 European Secondary Prevention Study Group. Translation of clinical trials into practice: a European population-based study of the use of thrombolysis for acute myocardial infarction. Lancet 1996;347:1203-7.

14 Grimshaw JM, Thomas RE, MacLennan G, et al. Effectiveness and efficiency of guideline dissemination and implementation strategies [monograph on the internet]. Southampton: National Coordinating Centre for Health Technology Assessment; 2004 [cited 2004 May 3]. Available from: http:// www.hta.nhsweb.nhs.uk/fullmono/mon806.pdf.

15 Fox KAA, Goodman SG, Klein W, et al. Management of acute coronary syndromes: variations in practice and outcome: findings from the global registry of acute coronary events (GRACE). Eur Heart $J$ 2002;23:1177-89.

16 Hasdai D, Behar S, Wallentin L, et al. A prospective survey of the characteristics, treatments and outcomes of patients with acute coronary syndromes in Europe and the Mediterranean basin: the Euro heart survey of acute coronary syndromes (Euro heart survey ACS). Eur Heart J 2002;23:1190-201

17 Rogers WJ, Canto JG, Lambrew CT, et al. Temporal trends in the treatment of over 1.5 million patients with myocardial infarction in the US from 1990 through 1999: the national registry of myocardial infarction 1, 2 and 3. J Am Coll Cardiol 2000;36:2056-63.

\section{ELECTRONIC PAGES}

\section{Heart Online case reports: www.heartjinl.com}

7 c he follow electronic only articles are published in conjunction with this issue of Heart.

\section{Giant right coronary artery aneurysm presenting as a} mediastinal mass

P Banerjee, T Houghton, M Walters, G C Kaye

Coronary artery aneurysms are commonly of atherosclerotic origin and are frequently asymptomatic. However, they may have varied presentations including angina, myocardial infarction, and sudden death. A case of a giant right coronary artery aneurysm presenting with acute myocardial infarction is presented, where the aneurysm appeared to be a mediastinal mass on transthoracic and transoesophageal echocardiography. Although computed tomography and magnetic resonance imaging of the heart suggested the correct diagnosis, definitive proof came from coronary angiography. Coronary artery aneurysms should be considered in the differential diagnosis of mediastinal masses.

(Heart 2004;90:e50) www.heartjnl.com/cgi/content/full/90/ 9/e50

\section{Methaemoglobinaemia after cardiac catheterisation: a rare cause of cyanosis}

L Kaendler, A Dorszewski, I Daehnert

Two young women had unexpected cyanosis a few hours after cardiac catheterisation for electrophysiological investigation. The first patient had atrioventricular septal defect, had undergone repeated surgical interventions, and was referred because of atrial flutter. The second patient had ablation of an accessory pathway in Wolff-Parkinson-White syndrome. Local anaesthesia was performed with $40 \mathrm{ml}$ prilocaine $2 \%$. Cyanosis with oxygen saturation of $85 \%$ developed in both patients a few hours after the electrophysiological investigation. The patients were transferred to the intensive care unit and for the first patient a considerable diagnostic effort was made to rule out morphological complication. Finally methaemoglobinaemia of $16.7 \%$ and $33.4 \%$, respectively, was found. Cyanosis resolved within 24 hours and did not reappear. Underlying glucose-6-phosphate dehydrogenase deficiency and erythrocyte-methaemoglobin reductase deficiency were ruled out. Physicians should be aware of this rare side effect of local anaesthetics in patients with unexpected cyanosis.

(Heart 2004;90:e51) www.heartjnl.com/cgi/content/full/90/ $9 / \mathrm{e} 51$ 